\title{
How Indonesia Realizes Human Resources That Can Compete Globally
}

\author{
Cahyo Adityo Irawan \\ s130118033@student.ubaya.ac.id
}

In general, employee productivity at work is directly proportional to high overall organizational competition when facing intense business competition, because all of these are closely related to the high and low levels of employee satisfaction with the company, such as more competitive salaries or wages, guaranteed career paths, the environment. comfortable work, and also the facilities offered. A superior company is a company that is competitive and adaptive to all changes. It should be understood that only companies that are always adaptive to change can survive and compete in the global era in the midst of a changing business environment, and can even grow and develop consistently. To make a change, companies often run massively, leaving behind the old strategies and methods, and move on to newer, more efficient methods. Companies that apply new methods and methods usually require business changes and human resource development. Transformation can work well if the company has a strong organizational culture. The corporate culture is very important because it functions as a strong adhesive between company members as well as the unification of the movements and steps of all elements in the company.

Currently, it is necessary to have an appropriate employee or worker selection system which is then developed in accordance with the needs of the work field and the demands of the organization. This development is usually carried out through training activities and understanding of corporate culture to improve employee knowledge and skills, including understanding of the overall organizational environment. This training is intended to provide new and existing employees with the skills they need to carry out their work. Training activities are usually always focused on the skills needed to carry out a current job, while employee development and management are long-term exercises to facilitate problem solving that usually arise in organizations. Over time, good employee performance must continue to be improved, and poor performance must be corrected immediately. Compensation should not be static but dynamic, which means following market prices and contingencies in an effort to motivate employees to perform better.

The quality of existing human resources is also inseparable from the poverty problem that has hit Indonesia to date and has become a complicated problem, although a number of data have shown improvement. The population dependency ratio in 2000 was $53.8 \%$ and in 2017 it was $48.1 \%$. This shows that the decrease in the number of burdens borne for 17 years does not appear to be linear with the reduction in the poverty rate that much. Commodity price fluctuations in recent years have had a major impact on the number of poor people, especially in some commodity-dependent regions. 
The government appears committed to remaining focused on work programs aimed at reducing poverty, unemployment and income inequality. However, the problem of poverty in Indonesia will not be successful if it is not taken seriously.

Another thing that is worrying about the low quality of human resources in Indonesia is the low formal achievement and the low basic competencies of students. Access to education, quality of education, and educational disparities are still far from expected. In terms of accessibility, there are still around five million school-age children who do not receive formal academic education at school. Those who receive formal education learn in classrooms that have not prepared their students to face the challenges of life in the 21st century. Improving the quality of learning is still limited to meeting the goals that are too low and out of date, namely only increasing learning outcomes scores. So it can be said that improving the quality of teaching and learning has not stopped being able to change human behavior and thinking patterns. Many people are still reluctant and afraid to take different and creative ways. They are afraid to be said to deviate or break the existing rules. So, they prefer to be followers and wait for other people to do it first. Likewise, something that is different will be considered wrong and deviant if it does not refer to standard operating procedures which ultimately makes employees do not think differently. Every individual has the right to be given the opportunity to develop uniqueness and have a better and more noble purpose than money, power, and rank. The same goal at work turns out to make it easier for employees to collaborate without coercion, considering that employee loyalty will produce very significant results. It should be understood that innovation does not mean finding a unique product, but can be done with strategic alliances, synergizing, and collaborating with business partners through strong coordination. In other words, creativity is a win-win solution, which depends heavily on the individual looking at issues from various sides and looking at different past solutions and transforming them into current situations because the times are very different from those of the past. Every company leader does have a big challenge in encouraging different individuals in the organization to realize their vision and mission in the midst of the dynamics of rapid change, including being able to bring a positive aura to all employees in the company for the creation of a strong organization. Motivating and engaging the work team seems easy to talk about, but the reality on the ground shows that it is not easy and it is very difficult to do. Employee involvement is strongly influenced by many factors, including a comfortable work environment, company policies, employee compensation, benefits of the facilities offered, the behavior of superiors and coworkers, and other forms that can surprise employees, such as during marriage, childbirth, illness, and others.

The leaders of large and medium-sized companies in Indonesia are aware of the increasingly fierce map of free competition and are trying to encourage human resources to be ready to compete at the global level, such as PT. Pertamina implements a Performance Management System where employees have the opportunity to convey their aspirations through coaching programs, dialogue days, and feedback sessions. Employees can also express their wishes to 
moving to an area through an international job placement mechanism. Furthermore, the fulfillment of global leaders and global players can be done through a business leader program.

Company leaders benefit more if they have qualified employees and a comfortable work environment, especially an environment that can accept differences of opinion and also support innovation. The combination of commitment and employee satisfaction is proven to be able to increase the productivity of company performance. Organizations must continue to transform, both in seeking innovative business leaps and in carrying out continuous development and improvement. Strategic transformation will be challenging, especially in aligning the new strategic direction with the existing organizational conditions, considering that today's competition demands the quality of everything that exists. (Tayibnapis, Wuryaningsih, \& Gora, 2018)

\section{References}

Tayibnapis, AZ, Wuryaningsih, LE, \& Gora, R. (2018, August). Indonesia's Efforts to Achieve Globally Competitive Human. International Journal of Humanities and Social Science Invention, 07 (08), 01-06. 